\title{
CARACTERIZAÇÃO MORFOMÉTRICA E VARIABILIDADE HIDROLÓGICA DE TRÊS BACIAS HIDROGRÁFICAS INSERIDAS EM DIFERENTES FORMAÇÕES GEOLÓGICAS NO MUNICÍPIO DE ITACARÉ, BAHIA
}

\author{
Sirleide Batista dos Santos ${ }^{(a)}$, Felipe de Souza Pimenta ${ }^{(a)}$, Paulo Fernando Meliani ${ }^{(b)}$ Maria \\ Eugênia Bruck de Moraes ${ }^{(\mathrm{c})}$
}

(a) Programa de Pós Graduação em Desenvolvimento Regional e Meio Ambiente, Universidade Estadual de Santa Cruz.email: sirleidegeo@ gmail.com

(a) Programa de Pós Graduação em Desenvolvimento Regional e Meio Ambiente, Universidade Estadual de Santa Cruz.email: felipepimenta93@outlook.com

(b) Departamento de Ciências Agrárias e Ambientais, Universidade Estadual de Santa Cruz.email: paulomeliani@ hotmail.com

(c) Departamento de Ciências Agrárias e Ambientais, Universidade Estadual de Santa Cruz.email:eugeniabruck@hotmail.com

\section{EIXO: BACIAS HIDROGRÁFICAS E RECURSOS HÍDRICOS: ANÁLISE, PLANEJAMENTO E GESTÃO}

\begin{abstract}
Resumo
A caracterização morfométrica possibilita o entendimento da dinâmica ambiental de bacias hidrográficas, quecontribui para o melhor aproveitamento dos recursos naturais, associados ao contexto das bacias observadas. Este trabalho objetiva identificar as características morfométricas, bem como, analisar a variabilidade hidrológica das bacias do Piracanga, Tijuípe e Tijuipinho no município de Itacaré, Bahia. Os índices morfométricos foram determinados por informações contidas nas imagens Topodata de 30 metros de resolução espacial, Já a caracterização hidrológica, foi derivada a partir dos dados fluviométricos, estimados a partir de modelagem com base na pluviosidade, temperatura e área superficial das bacias. Desse modo, o estudo aponta que as bacias apresentam pouca suscetibilidade à enchentes devido ao seu formato alongado. $\mathrm{O}$ maior escoamento superficial apresentado para a bacia do Piracanga, e o menor escoamento superficial apresentado para as demais bacias reforçam que o comportamento hidrológico coincidiu com os aspectos físico ambientais das mesmas.
\end{abstract}

Palavras chave:hidrologia, morfometria, drenagem, escoamento superficial.

\section{Introdução}

Entende-se por bacia hidrográfica um conjunto de terras drenadas por um rio principal e seus afluentes, formada nas regiões mais altas do relevo e por divisores de água(BARRELA et al.,2001). Sua identificação se faz, comumente, por meio da interpretação de cartas topográficase de fotografias aéreas verticais, sempre com o controle de pesquisas de campo e com oauxílio de geoprocessamento e de outros produtos de sensoriamento remoto, como imagensde satélite e de radar (SPANGHERO; MELIANI; MENDES, 2015). Reconhecendo a viabilidade da bacia hidrográfica como unidade de estudo e de gestão, 
como previsto na Política Nacional de Recursos Hídricos, instituída pela Lei $\mathrm{n}^{\mathrm{o}} 9.433$ de 1997,sãofundamentaisos diversos estudos e conhecimentos gerados a respeito desta temática.

Menezes et al. (2014) destacam que a caracterização morfométrica de uma bacia permite prever o grau de vulnerabilidade da mesma a fenômenos extremos, como enchentes e inundações, representa ponto de partida para estudos referentes à dinâmica ambiental, possibilitando, ainda, o melhor aproveitamento dos recursos naturais.E neste contexto destaca-se a viabilidade dos dados morfométricos, uma vez que, podemfornecer indicadores físicos específicos para um determinado local, de forma a qualificarem as alterações ambientais(ANTONELLI; THOMAZ, 2007).

De modo mais amplo, as características morfométricas do padrão de drenageme do relevo refletem algumas propriedades do terreno, como infiltração edeflúvio das águas das chuvas, e expressam estreita correlação com a litologia,estrutura geológica e formação superficial dos elementos que compõem asuperfície terrestre (PISSARA et al., 2004). As alterações sob a cobertura vegetal promovem mudanças bruscas sob o escoamento superficial de uma bacia e o regime pluviométrico pode agravar esses efeitos (TUCCI; CLARKE, 1997). Santos et al. (2012) salientam que as características físicas e também as bióticas, principalmente àquelas relacionadas com a cobertura vegetal do solo, desempenham importante papel nos processos relacionados à fase terrestre do ciclo hidrológico, influenciando, dentre outros, a infiltração, a evapotranspiração, os escoamentos superficial e subsuperficial e a quantidade de água produzida como deflúvio.

As bacias dos rios Piracanga, Tijuípe e Tijuipinho, estão inseridas ao longo da faixa litorânea do município de Itacaré, Bahia. Desde os anos 1990, esse município têm passado por transformações sócioespaciais significativas em função da inserção da economia do turismo. As particularidades morfológicas de seu terreno, a presença de cobertura florestal primária da Mata Atlântica que recobrem muitos morros e a função de abastecimento humano que alguns rios desempenham, elevam ovalor paisagístico e ecológico desse município (MELIANI, 2012).Segundo Gomes et al. (2012), cerca de 11\% da área desse munípio encontra-se recoberta por um mosaico de áreas protegidas destacando-se a Área de Proteção Ambiental da Costa de Itacaré/Serra Grande e o Parque Estadual da Serra do Condurú.

Diante dessascircunstâncias este trabalho tem a finalidade de caracterizar e comparar alguns aspectos morfométricos e hidrológicos das bacias dos rios Piracanga, Tijuípe e Tijuipinho, assim como analisar a variabilidade hidrológica das mesmas ao longo do período aproximado de meia década, considerando dados estimados de chuva e vazão. O propósito da escolha dessas bacias, justifica-se 


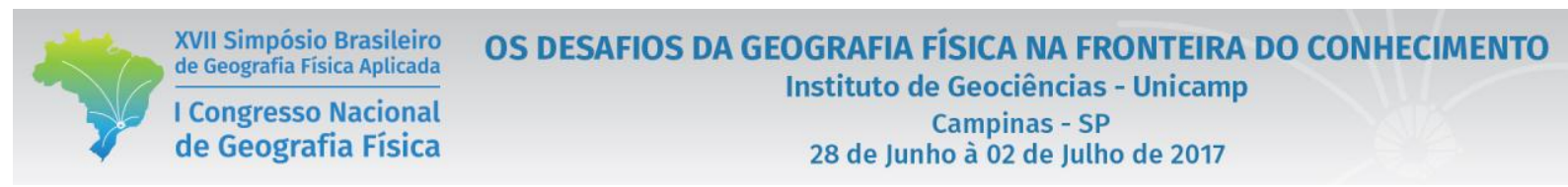

pelarepresentatividade delas para o município de Itacaré, pela proximidade entre as mesmas e diferenças nas tipologias do embasamento geológico e de ocupação do solo.

\section{Procedimentos metodológicos}

As bacias dos rios Piracanga e Tijuípe/Tijuipinholocalizam-se nos pontos extremos do litoral do município de Itacaré(Figura 1), que possui extensão costeira de aproximadamente 22,5 km situando entre as latitudes $14^{\circ} 13^{\prime}$ S e $14^{\circ} 25^{\prime}$ S, estende-se da foz do rio Piracanga (limite norte com o município de Maraú) até a foz do rio Tijuípe (limite sul com o município de Uruçuca). Diante desse aspecto, o relevo costeiro apresenta dois setores com feiçõesmorfológicas distintas: um setor Norte, da embocadura do rio Piracanga até a do rio de Contas, e um setor Sul, entre a foz do rio de Contas e a do rio Tijuípe. No setor Norte, as formas de relevo estão associadas a um domínio de depósitos quaternários, enquanto que o setor Sul apresenta como

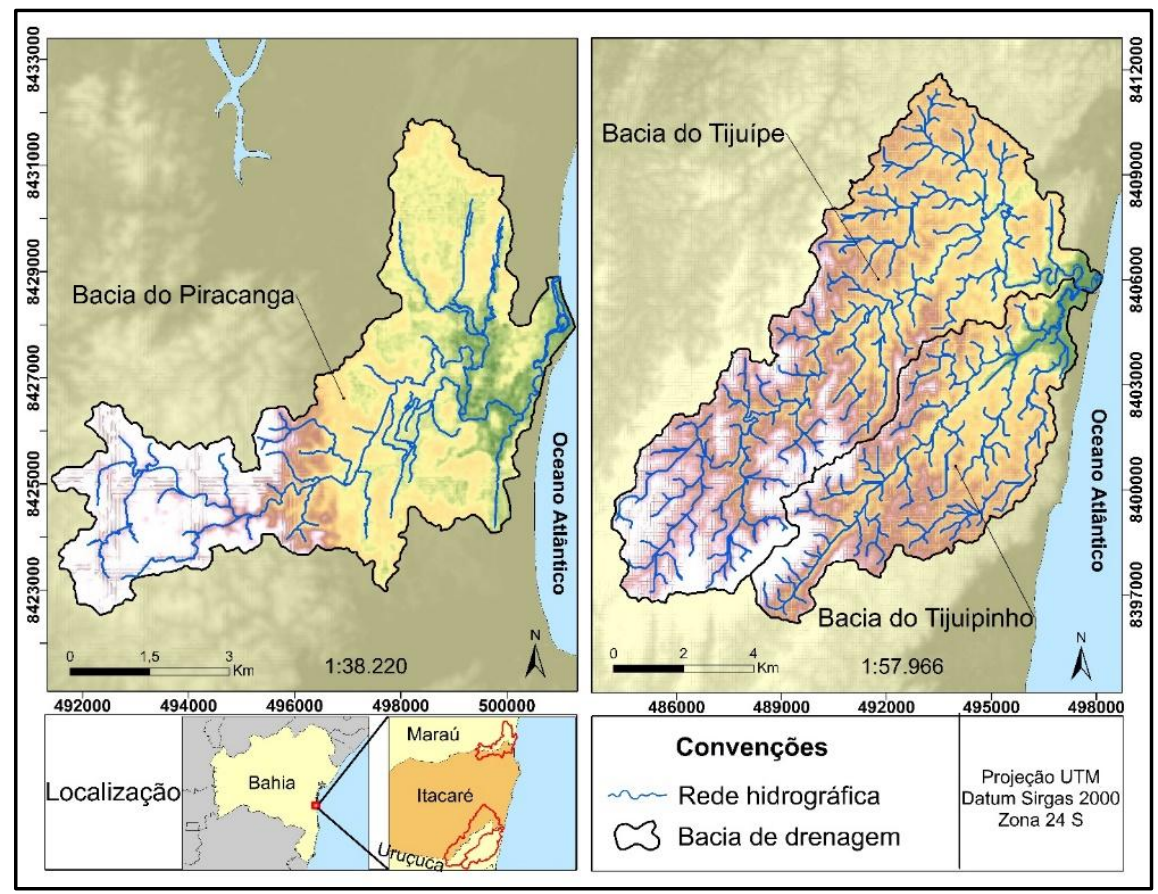

característica fundamental o embasamento cristalino pré-cambriano em contato com o mar (MELIANI, 2012).

Figura 1 - Localização das bacias dos rios Piracanga, Tijuípe e Tijuipinho entre os municípios de Maraú, Itacaré e Uruçuca no Sul da Bahia. Fonte: Topodata, USGS (2017). 
O curso do rio Piracanga é meandrante na planície costeira, percorre cerca de $2 \mathrm{~km}$ quase paralelamente a linha de costa, antes de romper a restinga e desembocar no Oceano Atlântico. Nos domínios cristalinos, as planícies são incipientes e ocorrem na forma de pequenas praias, que possuem maior expressividade espacial quando associadas às planícies flúvio-marinhas existentes na embocadura dos rios da bacia do Tijuípe/Tijuipinho (MELIANI, 2012).

A caracterização morfométrica da bacia do Piracanga foi norteada a partir da manipulação no Sistema de Informação Geográfica (SIG) ArcGIS 10.1,de imagens Topodata (Shuttle Radar TopographyMission, com30m de resolução espacial)(USGS, 2017). As imagens foram submetidas aotratamento hidrológico realizado a partir da extensãoarcHydro, que conduz a geração de um modelo hidrologicamente consistente permitindo determinar a orientação e as áreas de acumulação do fluxo hidrológico, fundamentais à delimitação da rede hidrográfica e contorno da bacia. A restituição definitiva da rede hidrográfica foi complementada através da interpretação de imagens de resolução espacial submétrica (entre 30 e $60 \mathrm{~cm}$ ) disponíveis no banco de dado online do SIG, além da consulta ao documento cartográfico elaborado por Mendonça (1979) em escala de 1:108.000. Também foram utilizadas informações derivadas de mapeamentos temáticos como:geologia na escala de 1:1.000.000 (CPRM, 2003), solos e vegetação em escala de 1: 1.250.000 (INEMA, 2014), a fim de proporcionar análises integradas dos componentes físico ambientais das bacias com alguns resultados gerados.

Os índices morfométricosforam determinados tendo em base informações contidas a partir da mensuração da área superfícial, rede hidrográfica ealtimetria das bacias em questão, considerando-se alguns conceitos e aplicações encontrados em literaturas específicas (HORTON, 1945; STRAHLER, 1952;1957; MILLER, 1953; SCHUMM, 1956; CHRISTOFOLETTI, 1974), alguns índices comumente utilizados como o índice de circunlaridade, o coeficiente de compacidade e o fator de forma, indicama tendência geométrica do formato de uma bacia, importante no controle de seu comportamento hidrológico. Da mesma forma que a desndidade de drenagem e hidrográfica e o coeficiente de manutensão inferem a capacidade hídrica da bacia em função das condições geológicas da mesma.Para fins de comparação, os dados morfométricos das bacias do Tijuipe e Tijuipinho foram obtidos através do trabalho de Spanghero, Meliani e Mendes (2015), exceto para o fator de forma eas curvas e integrais hipsométricas.

A curva hipsométrica permirte inferências comparativas entre diferentes bacias, através de estimativas sobre estágio de desenvolvimento geomórfico da bacia de drenagem, sendo a maturidade geológica da bacia indicada pela concavidade da curva hipsométrica(STRAHLER, 1952). Harlin (1978) descreve sua representação, através de uma função polinomial contínua, a integral hipsométrica, segundo Strahler (1952) é obtida pela integração da função polinomial que origina a curva hipsmétrica.As curvas e as 
XVII Simpósio Brasileiro de Geografia Física Aplicada

I Congresso Nacional de Geografia Física
OS DESAFIOS DA GEOGRAFIA FÍSICA NA FRONTEIRA DO CONHECIMENTO

Instituto de Geociências - Unicamp

Campinas - SP

28 de Junho à 02 de Julho de 2017

integrais hipsométricas foram determinadas a partir das informações altimétricas derivadas das imagens topodata, através auxílio da extensão Cal Hypso(PÉREZ PEÑA et al., 2009) para a versão 10.1 do SIG ArcGIS.

Os dados pluviométricos (Tropical Rainfall Measuring Mission, TRMM, 3B42) e de temperatuea (GLDAS-Global Land Data Assimilation)ambos com resoluçãoespacial de $0,25^{\circ}$, disponíveis na plataforma Giovanni(KUMMEROW et al. 2000; NASA, 2015) foram manipulados em ambiente SIG, considerando o período aproximado de meia década (2012 a 2016). A vazão foi estimada com base em um modeloclimatológico desenvolvido por Schreiber(1904),considerando a precipitação mensal (mm), temperatura $\left({ }^{\circ} \mathrm{C}\right)$ e área de drenagem $\left(\mathrm{Km}^{2}\right)$. A precipitação média mensal e sua respectiva vazão, permitiramestimar os valores acumulados anuais no intervalo de tempo considerado eo coeficiente de escoamento foi derivado a partir relação entre vazão e volume precipitado.

\section{Resultados e Discussão}

Considerando as informações disponíveis na Tabela I, sobre as características geométricas, a área superficial das bacias apresenta diferenças significativas.

Tabela I - Características morfométricas das bacias dos rios Piracanga, Tijuípe e Tijuipinho

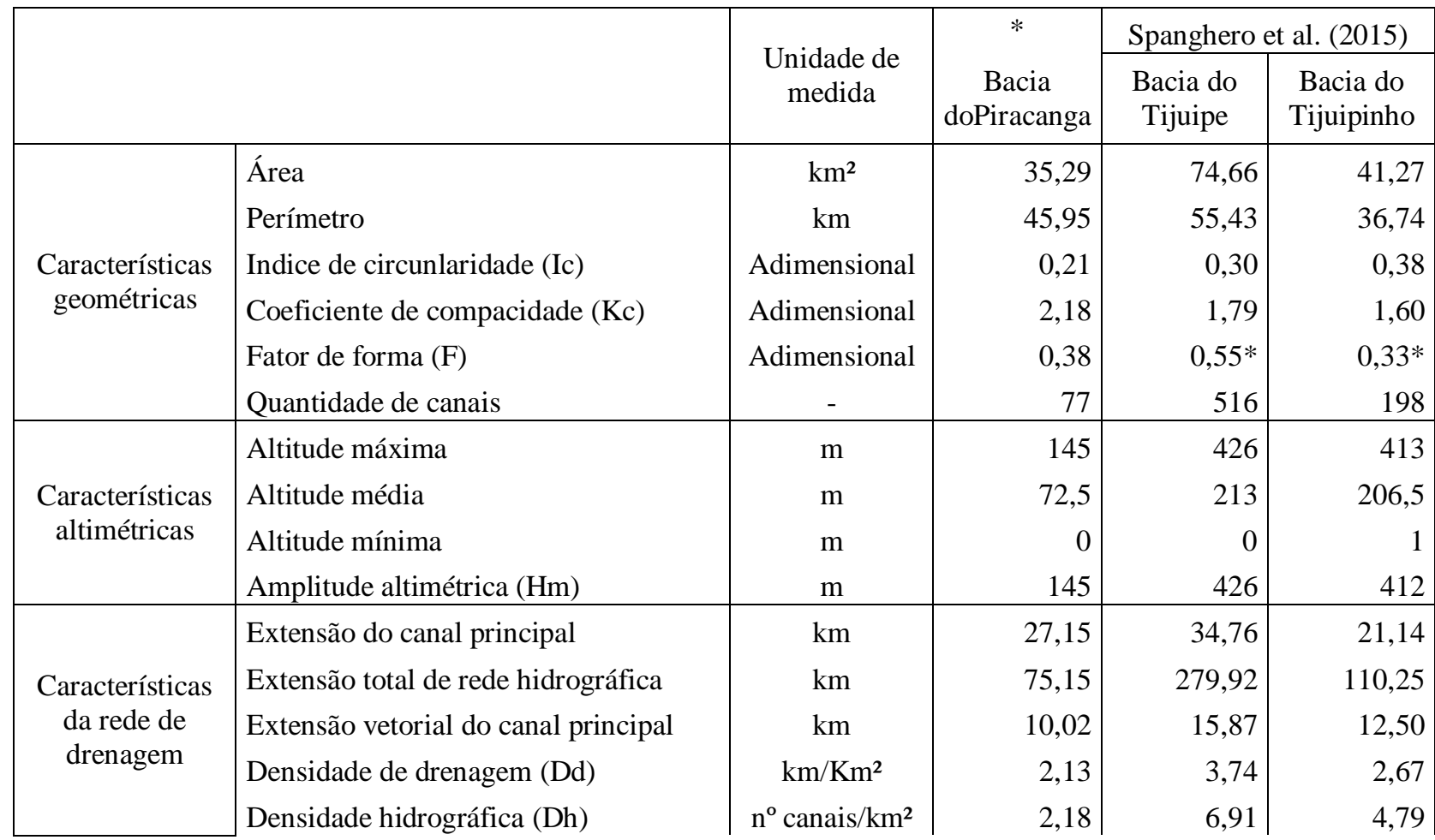




\begin{tabular}{|l|c|r|r|r|} 
Coeficiente de manutensão $(\mathrm{Cm})$ & $\mathrm{m}^{2} / \mathrm{m}$ & 470 & 374 & 267 \\
Ordem da bacia & - & 4 & 5 & 4 \\
\hline
\end{tabular}

* Valores obtidos pelo presente trabalho

A bacia do Tijuípe possui aproximadamente o tamanho da soma das áreas das demais bacias com uma pequena diferença de cerca de $2 \mathrm{~km}^{2}$. Os $\mathrm{Kc}$ encontrados para as bacias indicam que elas possuem formas alongadas,que neste caso, são diretamente proporcionais com a irregularidade de uma bacia. Um coeficiente mínimo igual a uma unidade corresponderia a uma bacia circular e, para uma bacia alongada, seu valor é significativamente superior a um (VILLELA; MATTOS 1975). O Kc das bacias do Piracanga, Tijuípe e Tijuipinhoassociados aos respectivos fatores de forma, $\mathrm{F}=0,38, \mathrm{~F}=0,55$ e $\mathrm{F}=0,33$ indicam a pouca suscetibilidade dessasbacias a enchentes. O resultado desses valores é reforçado pelo índice de circularidade (IC) das três bacias com valores inferiores à 0,40, que diante disso, Borsato (2005) destacaque valores menores que 0,51 indicam tendência alongada da bacia de drenagem e favorecimento do processo de escoamento superficial. Dessa maneira o Ic tende para uma unidade à medida que a bacia aproxima-se a forma circular e diminui a medida que a forma torna-se alongada (CARDOSO et al., 2006).

Spanghero, Meliani e Mendes (2015) salientam que não existe consenso na literatura sobre as classificações de valores de densidade de drenagem para bacias hidrográficas. De acordo com Villela e Mattos (1975), a densidade de drenagem de bacias hidrográficas varia de $0,5 \mathrm{~km} / \mathrm{km}^{2}$, caracterizando como bacia pouco drenada, a $3,5 \mathrm{~km} / \mathrm{km}^{2}$ ou superior (bacias bem drenadas).Deste modoé possível dizer em que as bacias do Piracanga e Tijuipinho apresentam drenagem média $\left(2,13 \mathrm{~km} / \mathrm{km}^{2}\right.$ e 2,67 km/km² respectivamente), enquanto que a bacia do Tijuípe apresenta drenagem alta $\left(3,74 \mathrm{~km} / \mathrm{km}^{2}\right)$. Dentre as três bacias, a ordem crescente desses valores, coincide com os tamanhos das mesmas, com a quantidade de canais mapeados e com a tipologia do embasamento geológico, destacando a predominância do terreno cristalino para aquela com valor superior, e terrenos mais permeáveis para a bacia com valor inferior.

Christofoletti (1974) aponta que emcertas condições climáticas, o comportamento hidrológico das rochas repercute na densidade de drenagem. Nas rochas mais resistentes a infiltração, há condições favoráveis para o escoamento superficial, possibilitando a modelagem de canais, como entre as rochas clásticas de granulação fina, e, como consequência, densidade de drenagem mais elevada, o contrário também ocorre com as rochas de granulometria grossa. A densidade hidrográfica é um índice resultante da relação entre a quantidade de canais de uma bacia e a sua área superficial, denominado por Christofoletti (1974),como densidade de rios e tem como finalidade comparar a frequência ou a quantidade de cursos d'água existentes em uma área de tamanho padrão como, por exemplo, o km². Segundo Teodoro et al (2007) menos que 1 canal por $\mathrm{km}^{2}$ apresenta baixa densidade hidrografica eeste aspecto, a bacia teria pouca 
capacidade de gerar novos cursos d'água.Os resultados indicam mesmo padrão, para os valores de Dd, sendoque a bacia do Piracanga e a bacia do Tijuípeobtiveram os valores extremos e a bacia do Tijuipinho com valor mediano, indicando a influência dos mesmos fatores apontados para o resultado da Dd, além da variação da extensão total dos canais de drenagem acompanhando o mesmo padrão dos resultados anteriores.

O Coeficiente de Manutenção $(\mathrm{Cm})$ representa importante indicativo de mensuração de área mínima necessária para a manutenção de um metro de drenagem (SCHUMM, 1956).Spanghero, Meliani e Mendes (2015) destacam o Cm como um indicador derivado da Dd, importante para a caracterização do sistema fluvial, pois referem-se a drenagem natural das águas superficiais de uma bacia. Para tanto, os resultados indicam menor capacidade de manutenção de cada metro de canal na bacia do Piracanga (aproximadamente $470 \mathrm{~m}^{2}$ ), enquanto que a bacia do Tijuipinho essa capacidade é de aproximadamente 2 vezes maior em virtude de seu valor ser inferior, denotando pouca área para manutenção por cada metro de canal e consequentemente maior capacidade para tal, seguida da bacia do Tijuípe. Sendo assim, Granell-Péres (2001) reforça que um coeficiente de manutenção alto indica que a bacia não possui uma boa área para manutenção dos seus canais.Tais resultados acima indicam que do ponto de vista da estrutura do sistema fluvial as bacias apresentaram comportamentos diferenciados com relação ao escoamento superficial.

Meliani (2012) salienta que a influência da tectônica nas formas de relevo ao longo da linha de costa do município de Itacaré, na qual as três bacias estão inseridas, manifesta-se nas redes hidrográficas adaptadas à estrutura geológica, principalmente no sentido S/SO-N/NE, acompanhando fraturas, falhas ou sequências de dobramentos.Considerando as características do relevo, aselevadas amplitudes altimétricas das bacias repercutiram a configuração das suas redes de drenagem, uma vez que estas são bacias exorréicasque apresentam cotas mínimas no nível do mar, enquanto que, a bacia do Tijuipinho, que deságua noTijuipe apresenta cota mínima com incremento de apenas uma unidade em relação às demais. A análise geomorfométrica das bacias, através das curvas e Integrais Hipsométricas (Figura 2) revelaram a interferência de diferentes fatores no aspecto geral do relevo das mesmas. Strahler (1952) destaca a fase Manadnock posterior ao equilíbrio alcançado na maturidade do terreno de uma bacia, caracterizada por valores de Integrais Hipsométricas (Hi) inferiores a 0,4, faixa compreendida entre as $\mathrm{Hi}$ das bacias em questão. Entretanto apesar dos valores das integrais hispsométricas indicarem processos que promoveramo desgaste do volume do terreno ao longo do tempo, essa relação não ocorre predominantemente nas trêsbacias. 

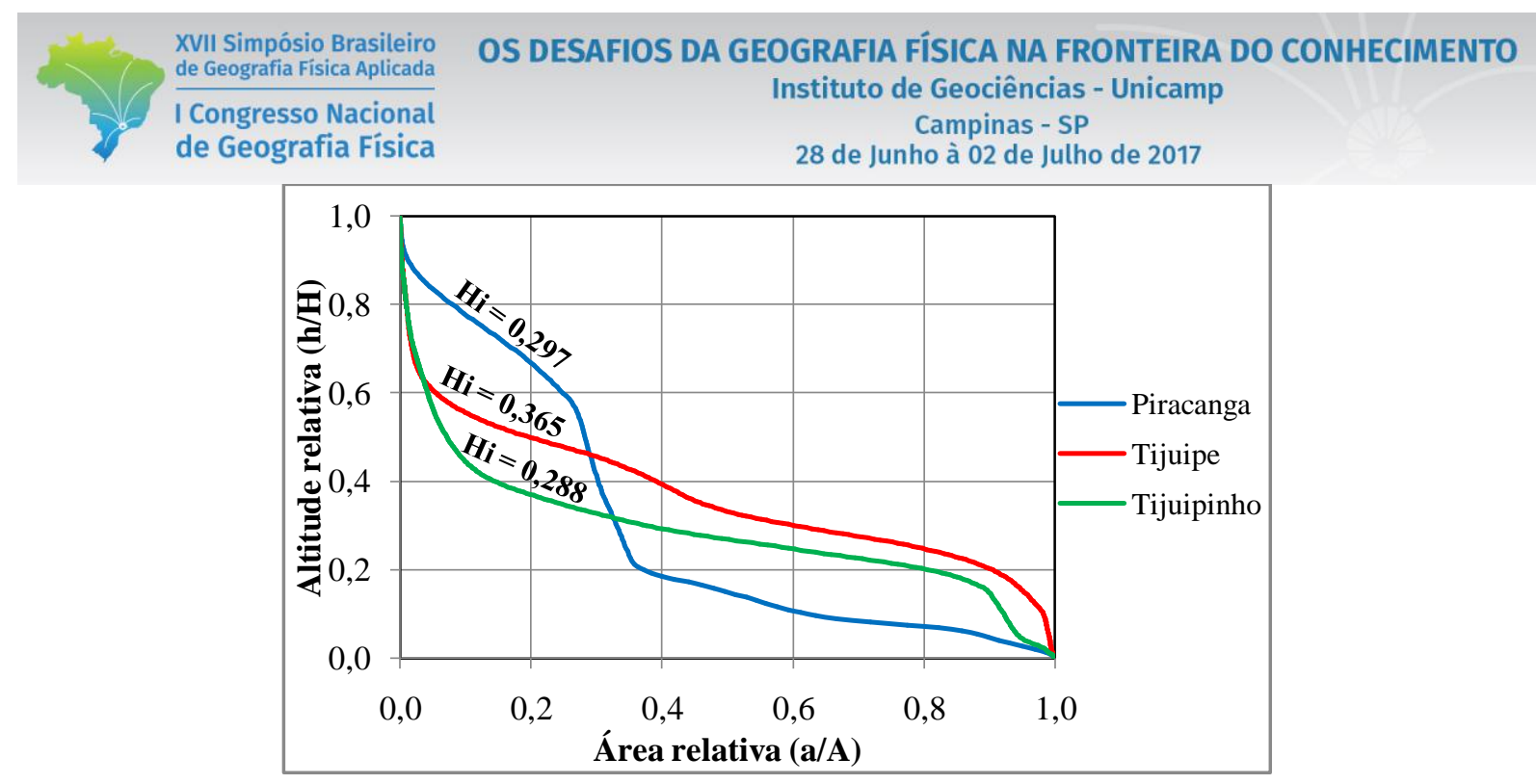

Figura 2 -Integral e curva hipsométrica das bacias dos rios Piracanga, Tijuípe e Tijuipinho

A bacia do Tijuípe, com valor superior $(\mathrm{Hi}=0,365)$, é ocupada pela unidade geológica mais antiga, de idade Neoarqueana, composta marjoritariamente por gabros (CPRM, 2003), apesar de a mesma apresentar a concavidade mais homogênea, tais fatores indicam que mesmo o longo tempo de esposição à dinâmica externa, a resistência do material pode ter desfavorecido o desgaste do volume rochoso. Mesmas características do material geológico se aplicam a bacia do Tijuipinho $(\mathrm{Hi}=0,288)$, porém esta apresenta maior desgaste em relação aquela, já que, por ser composta pelo grupo barreiras e depósitos marinhos e continentais, unidades mais recentes (Oligoceno e Quaternário) (CPRM, 2003), apresentam maior suscetibilidade ao desgaste erosivo. Por último, a bacia do Piracanga, com aspecto curvilíneo mais heterogeneo, mesmo com convexidade mais proeminente, o valor intermediário $(0,297)$, sugere certo desgaste do modelado reforçado pela tipologia do material geológico composto essencialmente por sedimentos de origem marinha, continental (período Quaternário) e por depósitos detrito-lateríticos (período Neogeno) (CPRM, 2003).Contudo apesar das sutis diferenças constatadas através das integrais associadas as curvas, as três bacias ainda apresentam similaridade se comparadas aos valores obtidos por Strahler (1952) de acordo com a categorização dos estágios de evolução do terreno.

A previsibilidade da relação precipitação $(\mathrm{P})$ vazão $(\mathrm{Q})$ é explicada para a bacia do Piracanga levando em conta as médias mensais do período aproximado de meia década, por meio do $\mathrm{r}^{2}=0,95$ e considerando-se os valores acumulados anuais de ambas as variáveis $\left(\mathrm{r}^{2}=0,92\right)$. Mesmo coeficiente para as bacias do Tijuipe e Tujipinho a partir das médias mansais, e relação ainda mais estreita $\left(r^{2}=0,99\right)$ para ambas, a partir dos dados anuais. O compartilhamento dos mesmos coeficientes para as bacias do Tijuipe e Tijuipinho, refletem valores idênticos de precipitação, já que ambas, localizam-se nas mesmas quadrículas de acordo com os dados pluviométricos da missão TRMM (3842 v7).A alta correlação entre 
tais variáveis pode representar a baixa expressividade de fatores como temperatura e área de drenagem na interferência sobre o defluvio considerando o modelo para vazão utilizado, contudo tais interferências podem surgir em situações peculiares, dada certas condições.Conforme a figura 3, o período apresentou variabilidade temporale espacial entre as duas variáveis recíprocas, destacando-se umincremento contínuo da pluviosidade até 2014e comportamento mais heterogêneo nos dois últimos anos, sempre com predomínio pluviométrico na bacia do Piracanga, com cerca de $400 \mathrm{mma}$ mais sobre as outras duas bacias no .

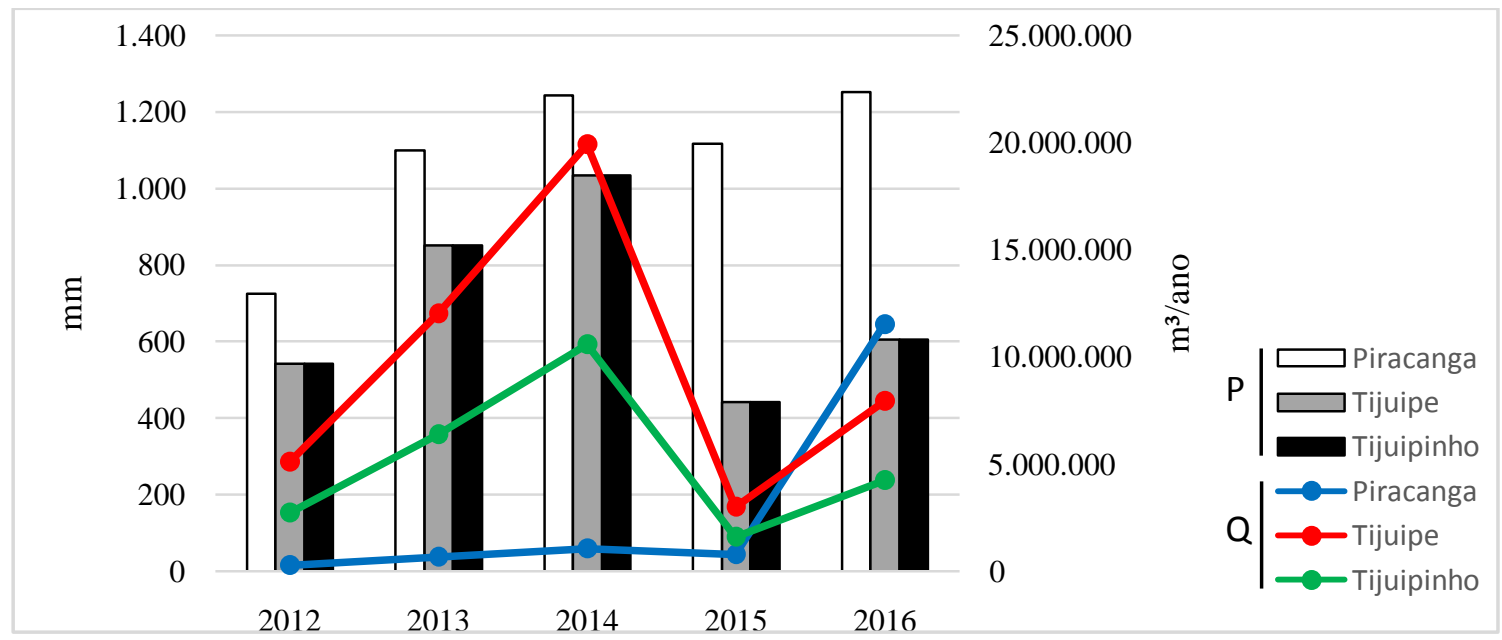

Figura 3 -Valores anuais de chuva e vazão para as bacias dos rios Piracanga, Tijuípe e Tijuipinho.

De forma geral, a vazão (Figura 3) apresentou comportamento temporal semelhante ao da precipitação e as diferenças são mais acentuadas entre as três bacias. Assim como a área superficial das bacias, a descarga na maior parte do tempo foi cerca de duas vezes superior para a bacia do Tijuípe em relação a bacia do Tijuipinho denotando a possível influência da área de drenagem sob a vazão, já que a precipitação é constante para ambas. Enquantoque a bacia do Piracanga apresentou as vazões inferiores da série até 2015,o pico atingido para esta bacia foi tardio em relação as outras duas, e o valor superior sob as demais bacias no último ano,resulta da contribuição das lâminas máximas de precipitaçãodo respectivo ano.

A variabilidade temporal dos valores de vazão e pluviosidade foi acompanhada pelo Coeficiente de Escoamento (Ce) para duas bacias (já que as bacias do Tijuipe e Tijuipinho apresentaram os mesmos Ce), considerando-se as médias anuais em valores relativos. De modo geral, constata-se possíveis diferenças no balanço hídrico entre as bacias, apesar de haver predominância de caminhos hidrológicos contrários ao escoamento, a bacia do Piracanga responde por aproximadamente o dobro da proporção de volume precipitado convertido em escoamento (14,5\%)em relação as demais bacias $(7,7 \%)$, indicandoum 


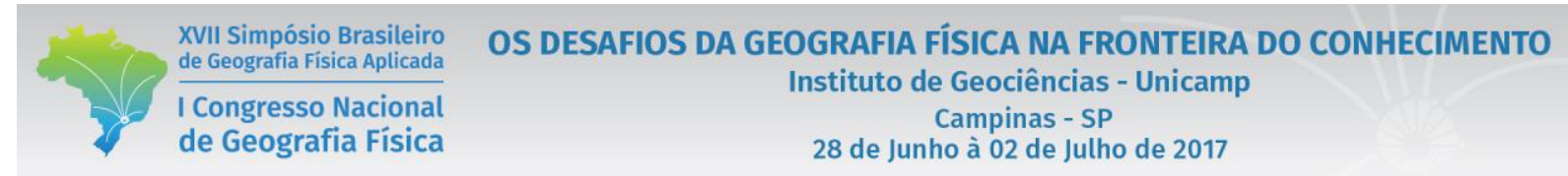

provávelmelhor aproveitamento do volume de água precipitado em termos de armazenamento das demais bacias.

Segundo Tucci \& Clarke (1997), as superfícies desprotegidas, tendem aumentar a capacidade de produzirem escoamento superficial, assim como o tipo de solo e sua condição de umidade. Apesar dos dados de vazão, derivados de modelagem, não considerarem a interferência do estado de ocupação da bacia nem de fatores topográficos, as variações no escoamento das bacias concincidem comas diferenças na cobertura florestal, sobretudo entre a bacia do Piracanga e as demais, aquela apresenta 19,4\% de área florestal,enquanto 52\% para a bacia do Tijuipinho e aproximadamente $70 \%$ no Tijuipe(Figura 4) (INEMA, 2014), reforçando a expressividade do escoamento na bacia menos florestada, onde há predominância de restingas $(35,3 \%)$ seguida por brejos $(28,3 \%)$ associados aos espodossolos hidromórficos e neossolos quartzarênicoscom os quais, desfavorecem a drenegem do solo, enquanto que as bacias mais florestadas, são essencialmente ocupadas por latossolos amarelos e vermelhos amarelos distróficos (Figura 4) (INEMA, 2014).

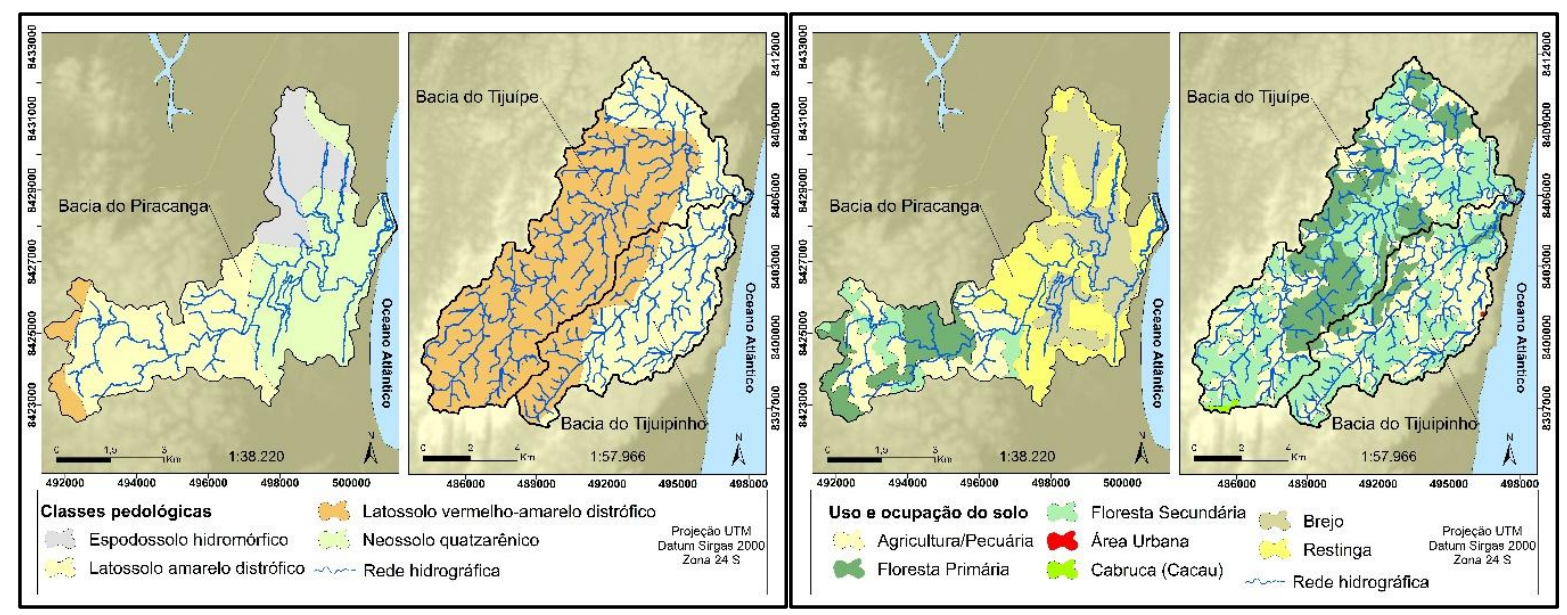

Figura 4 - Mapa pedológico (esquerda) e mapa de uso e ocupação do solo (direita) das bacias do Piracanga, Tijuípe e Tijuipinho

Fonte: Base cartográfica do INEMA, 2014

\section{Conclusão}

As carcterísticas do sistema fluvial refletiram a variabilidade dos tamanhos entre as bacias e a dimensão da rede hidrográfica associada, promovendo comportamentos diferenciados quanto a exposição a condições de escoamento superficial. As análises hipsométricas indicaram desgaste do relevo ao longo do tempo.Apesar dos dados hidrólogicos não estarem associados diretamente com determinados atributos físicoambientais das bacias,salienta-se que de modo geral, o comportamento hidrológico 
superficialcoincidiu comtais atributos.Neste aspecto, a bacia do Piracanga que apresenta menor cobertura florestale predominância de seu terreno em condição de má drenagem, reforçam o fato de o escoamento superficial ser maior nesta bacia. Enquanto que as demais bacias apresentam características contrárias as apresentadas na bacia do Piracanga. Neste caso, existe coerência para que as bacias do Tijuípe e Tijuipinho apresentem baixo escoamento superficial, uma vez que são marjoritariamentebem florestadas e apresentam boa drenagem oriunda da predominância de latossolos.

\section{Bibliografia}

ANTONELI, V; THOMAZ, E.L. Caracterização do meio físico da bacia do Arroio Boa Vista, Guamiranga-PR. Rev. Caminhos da Geografia, Uberlândia, v.8, n.21, p46-58, jun. 2007.

BARRELLA, W. et al. As relações entre as matas ciliares os rios e os peixes. In: RODRIGUES, R.R.; LEITÃO FILHO; H.F. (Ed.) Matas ciliares: conservação e recuperação. 2.ed. São Paulo: Editora da Universidade de São Paulo, 2001.

CARDOSO, C.A. et al. Caracterização morfométrica da bacia hidrográfica do rio Debossan, Nova Friburgo-RJ. Árvore, Viçosa, v.30, n.2, p.241-248, 2006.

CHRISTOFOLETTI, A. C. Geomorfologia. Edgard Blücher. São Paulo: Universidade de São Paulo, 1974, 149p.

CPRM - Companhia de Pesquisa de Recursos Minerais - Serviço Geológico do Brasil. Geobank: Mapa geológico do estado da Bahia, escala 1:1.000.000, 2003.

GOMES, R. L.; STRENZEL, G. M. R.; FERREIRA, H. M.; NEGREIROS, A. B.; GOES, I. M. A.; MATOS, I. S.; ASPRINO, M. Relatório técnico: geoprocessamento aplicado ao planejamento da paisagem do Mini Corredor Ecológico PESC-Boa Esperança. InstitutoFloresta Viva. Ilhéus. 104p. 2012.

HARLIN, J. M. Statistical moments of the hypsometric curve and its density function. Mathematical Geology.v. 10, n. 1 , p. 59-72, 1978.

HORTON, R. E. Erosional development of streams and their drainage basins: hydrophysical approach to quantitative morphology. Geol. Soc. AmericaBulletin. v. 56, n. 3, p. 275-370, 1945

INEMA - Instituto do Meio Ambiente e Recursos Hídricos. Governo da Bahia, banco de dados de 2014. Disponível em <http://www.inema.ba.gov.br/servicos/mapas-tematicos/?dl_page=2 >. Acessoem mar. 2017.

KUMMEROW, C. The Status of the Tropical Rainfall Measuring Mission (TRMM) after Two Years in Orbit. Journalof AppliedMeteorology,v. 39, p. 1965-1982,2000

MELIANI, P. F. Geomorfogênese do compartimento litorâneo do planalto cristalino da Bahia, Brasil: uma hipótese sobre a evolução do relevo costeiro do município de Itacaré. Revista Geonorte, edição especial, v. 2, n. 4, p. 498 509,2012

MENDONÇA, J. R. Fotointerpretação da hidrografia do município de Itacaré (BA). 297,00 x 420,00 mm. Escala 1: 108.000. Ilhéus, BA: CEPEC (Centro de Pesquisas do Cacau), 1979.

MILLER, V. C. A quantitative geomorphic study of drainage basins characteristic in the Clinch Mountain area. Technical Report. Dept. Geology, Columbia University, n. 3,1953.

NASA - National Aeronautics and Space Administration Goddard Earth Science Data Informationand Services Center (GES DISC). Tropical Rainfall Measurement Mission, 2015. Disponívelem: https://disc2.gesdisc.eosdis.nasa.gov/data/TRMM_L3/TRMM_3B42/doc/TRMM_Readme_v3.pdf Acesso: 10 fev. 2017. 
PÉREZ PEÑA, J.V.; AZAÑÓN, J. M.; AZOR, A. CalHypso: an ArcGIS extension to calculate hypsometric curves and their statistical moments. Applications to drainage basin analysis in SE Spain. Computers \& Geosciences., v. 35, n. 6, p. 1214-1223, 2009.

SANTOS, A. M. Et al. Análise morfométrica das sub-bacias hidrográficas Perdizes e Fojo no município de Campos do Jordão, SP, Brasil. RevistaAmbiente\&Água. v. 7, n. 3, 2012.

SCHREIBER, P. Über die BeziehungenzwischendemNiederschlag und der Wasserführungder Flüsse in Mitteleuropa. MeteorologischeZeitschrift. v. 21, p. 441-452,1904.

SCHUMM, S. A. Evolution of drainage systems and slopes in badlands of Perth Amboy. Geol. Soc. AmericaBulletin., v. 67, p. 597-646, 1956.

SPANGHERO, P. E. S. F.; MELIANI, P. F.; MENDES, J. S. Mapeamento hidrográfico de detalhe e análise morfométrica comparativa das bacias dos rios Tijuípe e Tijuipinho, litoral sul da Bahia. Caminhos de Geografia, Uberlândia. v. 16, n. 53, p. 101-117, 2015.

STRAHLER, A. N. Hypsometric (area-altitude) analysesoferosionaltopography. Geol. Soc. America Bulletin.v. 63, p. 1117-1142,1952.

STRAHLER, A. N. Quantitative analysis of watershed geomorphology. Transactions, American Geophysical Union.v. 38, n.6, p. 913-920, 1957.

TUCCI, C. E. M.; CLARKE, R. T.Impacto das mudanças da cobertura vegetal no escoamento: revisão. Revista Brasileira de Recursos Hídricos.v. 2, n. 1, p. 135-152,1997

USGS - United StatesGeologicalSurvey. Shuttle Radar Topography Mission - MissionSummary. Disponível em: < https://lta.cr.usgs.gov/srtm/mission_summary >.Acesso:10 de fev. de 2017.

VILLELA, S.M.; MATTOS, A. Hidrologia aplicada. São Paulo: McGRAWHilldo Brasil, 1975. 245p. 